\title{
A CRÔNICA CRIOULA DE VERA DUARTE ${ }^{1}$
}

\section{THE CREOLE CHRONICLE OF VERA DUARTE}

\author{
Norma Sueli Rosa Lima²
}

1 Esse artigo faz parte de dois Projetos de Pesquisa em andamento na Universidade do Estado do Rio de Janeiro - UERJ, um aprovado pela Fundação de Amparo à Pesquisa do Estado do Rio de Janeiro - FAPERJ, que relaciona os romances de Vera Duarte e de Jorge Amado em busca das construções e desconstruções da alteridade mestiça, e outro, desenvolvido pelo Programa Institucional de Bolsas de Iniciação Científica - PIBIC, com o apoio do Conselho Nacional de Desenvolvimento Científico e Tecnológico - CNPq, que tem por objeto examinar as crônicas e as memórias dos autores supracitados.

2 Professora Adjunta do Departamento de Letras da Universidade do Estado do Rio de Janeiro - FFP. 
Resumo: 0 artigo tem por objetivo investigar, na escrita do único livro de crônicas de Vera Duarte, dicções híbridas próprias do gênero na sociedade cabo-verdiana, quando a crônica, metamorfoseada de gênero histórico a literário, é um dos instrumentos humanizadores de valorização das questões do cotidiano que tenciona o espaço rebaixado em que a mulher foi inserida nas sociedades patriarcais. Percebe-se que a autora, em A palavra e os dias, retrata o seu dia a dia pela via das subjetividades do cotidiano, ao documentar e analisar aspectos da sociedade crioula.

Palavras-chave: Vera Duarte, literatura-caboverdiana, crônica. 
Abstract: The article aims to investigate, in the writing of Vera Duarte's only chronicle book, hybrid dictions typical of the gender and the place of the feminine in Cape Verdean society, when the chronicle, metamorphosed from historical to literary genre, is one of the humanizing instruments of valuing the issues of everyday life that intends the lowered space in which women were inserted in patriarchal societies. It can be seen that the author, in The word and the days, portrays her daily life through the subjectivity of everyday life, when documenting and analyzing aspects of Creole society.

Keywords: Vera Duarte, Cape Verdean literature, chronic. 
As escritoras cabo-verdianas vêm ocupando espaço considerável após terem sido invisibilizadas há algumas décadas em publicações (não enquanto produções). Exemplos? Na Antologia organizada por Baltasar Lopes, como observou Simone Caputo Gomes (2019), em 1960, havia 100\% de autores masculinos; outra, de Jaime de Figueiredo em 1961, contendo 20 poetas e apenas uma cabo-verdiana, Yolanda Morazzo, fato que se repetirá tanto na seleção posterior de Manuel Ferreira (1975), em No reino de Caliban (Yolanda Morazzo entre 39 poetas) quanto na de Castro Segóvia, no Panorama de la poésie du Cap-Vert (1980) (GOMES, 2008). Em Os Jogos Florais 12 de setembro, de 1976, há 11 poetas, dentre os quais somente uma mulher, Vera Duarte. Atualmente, ainda não são expressivas as antologias que ao menos equiparem as autorias masculinas e femininas, como a poética organizada por Amosse Mucavele, A arqueologia da palavra e a anatomia da língua, de 2013. Falo de autoras premiadas, traduzidas no mundo todo, pesquisadas em dissertações de mestrado e em teses de doutorado, com produção cada vez maior, abrangendo poesia, conto, romance e crônica.

No ambiente da literatura produzida por mulheres em contextos pós-coloniais, entendo com outras pensadoras que o ato de elas tomarem para si a palavra é o reverso de terem sido, durante muito tempo, apenas as que foram escritas, para recuperar a feliz expressão de Lúcia Castello Branco e Ruth Salviano 
Brandão (1989), quando as retrataram, no final da década de 1980, como "passageiras da voz alheia". Tornaram-se, essas pioneiras escritoras, as atuais recriadoras do verbo e da consciência crítica, cujas escritas, que nasceram do vazio forçado, foram desenhando os próprios contornos. Ainda nos anos 1980, é preciosa a indagação com que Gayatri Spivak intitulou o seu artigo "Pode o subalterno falar?" (1985), quando a escrita considerada "inferior" estilhaça preconceitos reforçados pelo discurso patriarcal. No caso de Vera Duarte, em A palavra e os dias, ocorre o estilhaçamento de duplo preconceito: o da mulher e o da mulher que escreve crônica - também considerado um gênero menor.

Com tanta invisibilidade, não é de se estranhar que Maria Luísa de Sena Barcelos, poetisa da Ilha Brava que assinava os seus escritos como "Africana” e era irmã do historiador Cristiano de Sena Barcelos, não tenha conseguido deixar uma obra publicada. Na produção da literatura cabo-verdiana iniciada no século XIX, o primeiro romance publicado por uma mulher foi A louca do serrano, de Dina Salústio, em 1998. Antes, no campo da poesia, houve o nome de Yolanda Morazzo, que como declarou em entrevista de 1976, apenas conseguiu fazer circular o seu trabalho após o 25 de abril "quando já foi possível a publicação de alguns poemas de intervenção até então proibidos ou truncados" (ROZÁRIO, 1999, p. 43). Somente em 2006, Yolanda teve a sua obra reunida no volume Poe- 
sia completa - 1954-2004, pela editora Imprensa Nacional-Casa da Moeda. Cabe observar ter sido Antónia Gertrudes Pusich, oriunda da ilha de S. Nicolau, a que publica o livro em Portugal antes do aparecimento do prelo nas colônias.

Vera Duarte (Mindelo, Ilha de São Vicente, 1952) traz a versatilidade de ter percorrido, em sua trajetória literária, todos os gêneros. É autora de poesias: Amanhã amadrugada, 1993; O arquipélago da Paixão, 2001; Preces e súplicas ou os cânticos da desesperança, 2005; Exercícios poéticos, 2010; De riso e lágrimas, 2018; romances: A candidata, 2005; Reflexões sobre os Direitos Humanos: Construindo a Utopia, 2008; A matriarca, uma estória de mestiçagens, 2017; crônica: As palavras e os dias, 2013, e mais recentemente: Cabo Verde, um roteiro sentimental viajando pelas ilhas de Sodad, do Sol e da Morabeza (2019), com Suzana Duarte, e Contos crepusculares: metamorfoses (2020). Ela afirmou, em entrevista concedida na década de 90, que ser original da "Ilha do Porto Grande (como também é conhecida a ilha de São Vicente, marcada pela chegada e partida constante de navios trazendo pessoas de todas as partes do mundo) foi fundamental para as suas formação e idiossincrasia 'pois tendo nascido e crescido de olhos virados para ele [o 'Porto'] a abrir-se ao infinito por ele se plasmou o meu espírito aberto ao mundo'”. (ROZÁRIO, 1999, p. 93). 
0 fato de a escritora ser oriunda de nação formada, inicialmente, pelo africano escravizado da costa da Guiné-Bissau misturado ao luso colonizador e, posteriormente, a outros fluxos étnicos que aportaram nas ilhas, mereceu dela as seguintes reflexões realizadas no I Encontro de Escritores Cabo-verdianos, ocorrido em 1992:

Na nossa génese - ainda tão recente - estão elementos de origem africana e de origem europeia, com mesclas de judeu e hindu. Não temos uma cultura do tipo tradicional africano como não temos do tipo europeu, americano ou hindu. Temos elementos de todos, com preponderância do africano, mas genuinamente não temos de nenhum, pois os apports culturais perderam naturalmente alguma da sua genuinidade ao serem transplantados dos continentes respectivos para as ilhas. E era natural que assim fosse. A própria natureza das ilhas, em tudo diferente dos continentes, exigia adaptação dos costumes trazidos. A nossa árvore genealógica tem brancos e pretos à mistura. (...) quem é mais caboverdiano: a minha mãe que tem a pele clara ou o meu pai que tem a pele escura?" (DUARTE, 1994, p. 13). Cabe observar que, tanto no Brasil quanto em Cabo Verde, conforme observei na minha tese de doutorado a ser lançada em livro, os fluxos étnicos foram encarados, ao mesmo tempo, como conflito e ganho, já que desenvolveram uma multiplicidade. Naquela pesquisa, desenvolvida na Universidade Federal Fluminense, recorri ao 
Manifesto Antropófago, de Oswald de Andrade, para utilizar a metáfora do canibal que precisava devorar a imagem falsa que dele o discurso hegemônico fizera, porque, na verdade, o potencial cultural e a originalidade dos povos com história de subjugação não residiam em uma exclusividade (nem europeia, nem africana e, no caso brasileiro, nem indígena), mas sim em uma combinação (LIMA, 2000). Silviano Santiago, no clássico e sempre necessário "O entre-lugar do discurso latino-americano", de 1978, observou que o colonialismo engendrou

uma nova sociedade, a dos mestiços, cuja principal característica é o fato de que de que a noção de unidade sofre reviravolta (...) em favor de uma mistura sutil e complexa (...) uma espécie de infiltração progressiva (...) ou seja, abertura do único caminho possível que poderia levar à descolonização. (SANTIAGO, 2000, p. 15)

Pensar sociedades de etnias mescladas, em termos contemporâneos, possibilita enveredar por outras reflexões como a de "literatura-mundo", a qual, segundo o crítico literário português Pires Laranjeira, foi utilizada pela escola de Harvard para classificar a literatura que se deseja sem fronteiras, mestiçada, transnacional, viajante ou mutante, concepção sintonizada com a modernidade líquida assentada no capitalismo deslocalizado. Naturalmente que não é essa a minha perspectiva para compreender as culturas crioulas. 
Nesse sentido, cabe o exame dos usos políticos para o conceito de mestiçagem em diferentes momentos no Brasil - no século XIX para incentivar o embranquecimento da população com Sílvio Romero; no XX para a suposta democracia racial em Gilberto Freyre; e no XXI nas discussões ancoradas nos Estudos Culturais e no Pós-Colonialismo. Em Cabo Verde não houve essas perspectivas, na medida em que a própria sociedade já se constituía naturalmente crioula.

No exame de correntes que prevem a fatal mistura cultural no mundo, tenho por objetivo tensionar suposições na reflexão de contatos sem barreiras ou muros, como ponderou Laranjeira ao chamar a atenção para o fato de que etnias vistas pela via da alteridade e do respeito parecem constituir, infelizmente, projeto: "a apresentar uma utopia, pois o estado atual é outro, mantendo as velhas divisões e choques de interesses de estratos diferenciados dos povos." (2015, p. 28). Nesse sentido, me aproximo do que a escritora afro-americana Toni Morrison recentemente determinou como "processos de outremização", quando os negros são lançados à categoria do outro, ocupando, desse modo, espaços subalternos ou marginais nas sociedades de base colonizatória. Nas crônicas crioulas de Vera Duarte, há de se observar a valorização da mistura, não como apagamento, mas como contribuições culturais paralelas em interseção.

Achille Mbembe, em A crítica da razão negra, sinalizou a importância do próprio africano repensar o 
seu conceito da África, construído em bases de oposição ou de ligação a pressupostos ocidentais. 0 filósofo camaronês propôs que ao conceito de negro, grupo étnico excluído e inventado pelo discurso político do poder, se unissem outros segmentos igualmente excluídos (o que ele denominou como "devir negro"): "[...] os riscos sistemáticos aos quais os escravos foram expostos durante o primeiro capitalismo constituem agora, se não a norma, pelo menos o quinhão de todas as humanidades subalternas" (2018, p. 17).

0 negro e a raça se constituíram como construções imaginárias inacabadas, espectadoras de sua própria existência inventada, nas ambiências tanto de sua coisificação, quanto do seu pretenso enaltecimento. Isso foi realizado pelas Vanguardas Europeias, por exemplo, no símbolo do "primitivismo", idealizado como motivo artístico do século XIX. O filósofo francês Rousseau, no século anterior, também idealizara o "indígena" na perspectiva do "bom selvagem", do mesmo modo que o mestiço, posteriormente, seria pensado e descrito do ponto de vista de concepções fantasiosas, utilizado, muitas vezes, para justificar a falaciosa ideia da inexistência do preconceito racial, quando inserido no discurso da "harmonia racial", no século passado. É nessa direção que segue a minha atual pesquisa, na inserção do conceito de mestiço em fresta a tensionar, tanto o discurso de branquitude, quanto o de negritude 
Volto à Vera Duarte para fornecer pequena biografia: formada em Direito pela Universidade de Lisboa (a primeira magistrada em Cabo Verde), desempenhou várias funções nas ilhas como desembargadora, ministra (para citar alguns cargos) e é detentora de muitos prêmios, como o atribuído pela Organização das Mulheres de Cabo Verde (OMCV), o Norte-Sul dos Direitos Humanos do Conselho de Europa. Teve seus poemas traduzidos em alemão, árabe, espanhol, francês, holandês, inglês, sueco (além de originais em língua cabo-verdiana e língua portuguesa), alguns foram musicados e objeto de diálogo com jovens poetas de Cabo Verde e do Brasil, que lhe dedicaram os livros Dialogando com a escrita de Vera Duarte (2015, Escola Secundária do Salineiro) e Combinando palavras com Vera Duarte (2014, Escola Estadual Otoniel Mota, Ribeirão Preto).

No seu único livro de crônicas, A palavra e os dias, organizado por Christina Ramalho, a escrita de Vera assume tons poéticos, memorialísticos e ativistas, para citar algumas dicções. A obra é composta por textos que foram publicados em Mujer, revista da organização das mulheres de Cabo Verde, e transmitidos através da Rádio Cabo Verde. Há, ainda, outros inéditos feitos especialmente para a edição. Ao trazer esse material para ser eternizado em livro, Ramalho colabora para a sua não dispersão em veículos distintos, além de resgatar o valor literário da crônica como retrato da sociedade crioula. 
Em sua origem histórica em Portugal, o relato cronístico testemunhou o confronto entre os mundos no ambiente das Grandes Navegações e apesar da intenção do seu rigor histórico, com a nomeação em Portugal de Fernão Lopes como o guarda e cronista-mor desses documentos reunidos na Torre do Tombo, cabe trazer a indagação de Silviano Santiago: "até que ponto as palavras dos europeus traduziam a verdade transparente?" (2000, p. 12). A linguista Eni Orlandi (1990) investigou, no discurso das descobertas e dos achamentos que davam a conhecer o Novo Mundo, a manipulação colonial, cujo produto mais eficaz foi o de revelar para a sociedade da época nativos como seres selvagens e sem história. No trajeto inverso, os outrora descritos naqueles documentos passaram a tecer os seus próprios fios de singularidade ou pluralidade histórica.

0 relato clássico do deus Cronos que destronou o pai Urano pode ser lido como a alegoria de que o tempo, em sua passagem fatal, a tudo engole. A origem etimológica da palavra grega chronos, da qual se originou o vocábulo cronista, concebe a ele, entretanto, magicamente reter e perpetuar o tempo. Antonio Candido possui um dos mais belos textos sobre a crônica, ao evidenciar o quanto esse gênero se ajustava à sensibilidade de todo o dia, principalmente por elaborar linguagem mais natural que ensina "a conviver intimamente com a palavra, fazendo que ela não se dissolva de todo ou depressa demais no contexto, 
mas ganhe relevo, permitindo que o leitor a sinta na força dos seus valores próprios". (1992, p. 15). Esse uso da palavra se aproxima da proposta modernista brasileira de ativar, na literatura, as linguagens da fala cotidiana como Oswald de Andrade deixou claro no Manifesto da Poesia Pau Brasil: "A língua sem arcaísmos. Sem erudição. Natural e neológica. A contribuição milionária de todos os erros." (1998, p. 66). Vera Duarte, a cronista de Cabo Verde, desse modo, desenha os dias nas palavras oralizadas e retém na escrita o tempo que o seu olhar apreende.

Para Jorge de Sá "a vida diária se torna mais digna de ser vivida quando a convivência com outras pessoas nos leva a olhar para fora de nós mesmos, descobrindo a beleza do outro" (1985, p.22). É essa a forma humanizada de Vera caminhar por sua sociedade crioula, revelando a beleza das pequenas coisas ou denunciando as grandes injustiças em diferentes tempos, tanto de quando ainda era menina ou de quando tão menina e independente era a sua nação. Nessa trajetória, os laços com o Brasil assumem proporção carinhosíssima pois a autora (seguindo, aliás, uma importante tradição de escritoras e escritores do arquipélago) reconhece no país irmão muito de Cabo Verde e da antropofagia das culturas que fez renascer outra sociedade mestiça, identificadíssimas com a herança comum africana.

Lembro que o termo crioulo designava o afro-brasileiro ou afrodescendente nascido no Brasil. 0 título 
desse artigo, entretanto, apreende a palavra na direção de culturas em contato visto que as crônicas de Vera Duarte não foram escritas em língua cabo-verdiana, mas transitam por uma sociedade crioula, refletindo-a.

É importante destacar, ainda, o olhar da autora que apreende os dias e as palavras do ponto de vista das subjetividades plurais emergentes, na via da hermenêutica do cotidiano, na procura de documentar e analisar aspectos da vida dos cabo-verdianos e das cabo-verdianas que

na emergência do privado e do cotidiano na cena dos estudos históricos permite mostrarse com toda força a presença dos "segmentos subalternos" e das mulheres e os deslocamentos produzidos pelo feminismo têm propiciado a assunção de novos temas e perfis que contam as experiências das mulheres e que nos permitem reconhecer a origem de crenças e práticas sociais que as estigmatizam. (GOMES, 2008, p. 6)

As mulheres cabo-verdianas são as primeiras transmissoras da cultura crioula, porque se ocupam da educação das crianças e a elas transmitem as tradições de Cabo Verde, inclusive no campo da oralidade, nas estórias contadas. Também a morna, símbolo da identidade das ilhas, é preservada pelas cantadeiras, cujo assunto é o próprio trabalho - a lavoura, a lavagem de roupa, o carregamento de mercadorias. Atualmente, outros temas a ela foram acrescidos, 
como o amoroso (crecheu) ou a saudade, conforme cantou Cesária Évora.

As crônicas-conversas de Vera revelam as mudanças pelas quais Cabo Verde passou, em suas diferentes situações político-sociais, primeiro como colônia de Portugal, depois como colônia disfarçada pelo discurso salazarista, que identificava as ilhas como "terras do além mar" e, finalmente, a partir de 1975, como nação independente. Cabe ressaltar que, poucos anos depois, o arquipélago aderiu, em novembro de 1979, à Convenção sobre a Eliminação de Todas as Formas de Discriminação em Relação às Mulheres (CEDAW), mas apesar dessa perspectiva em seu ordenamento jurídico assegurando que as mulheres ultrapassassem o lugar privado (mesmo quando assumiam o duplo papel no ambiente doméstico, devido à emigração em massa causada pelas dificuldades de sobrevivência no arquipélago, e atuando paulatinamente na esfera pública, inclusive atuando em espaços outrora destinados apenas aos homens), ainda há muito a conquistar.

Na publicação do Instituto Nacional de Estatística Mulheres e Homens em Cabo Verde, de 2017, há dados que evidenciam o desequilíbrio da participação de gênero, como o de $23.6 \%$ de mulheres para $76.4 \%$ de homens no parlamento ou o de $0 \%$ de mulheres presidentes de Câmara Municipal para 100\% de homens, entre outros, painel que: 
corrobora o que verificamos no campo literário no que se refere às aludidas antologias, quantidade de edições femininas, premiações, enfim, dispositivos legitimadores de um sistema: a vigência do discurso hegemônico de gênero (o masculino). (GOMES, 2019, p. 234)

É a própria Vera que afirma:

(...) o imperativo da busca pela sobrevivência econômica num país de escassos recursos naturais e vítima do abandono colonial fizeram com que as mulheres cabo-verdianas, desde cedo, tivessem uma ativa integração no mercado de trabalho. Mais do que isso, elas cedo também adotaram a via da emigração para resolver o problema da sobrevivência das suas famílias. (DUARTE, 2015, p. 233)

Existem diversas interlocuções em A palavra e os dias que são constantes em toda a obra da escritora, entretanto me concentrarei na que realiza com a sua própria pátria: na feita com os escritores (Baltasar Lopes - Oswaldo Alcântara/Nhô Baltas, Jorge Barbosa e Manuel Lopes, que fundaram a primeira revista moderna de Cabo Verde, Claridade), na efetuada com os direitos das mulheres e na existente com o Brasil. Temas presentes em quase todos os oito capítulos (que trazem epígrafes com trechos de poemas da própria autora), abordados mesmo fora dos eixos temáticos ("As ilhas, um país: ser cabo-verdiana"; "As mulheres; Outras lutas: público e privado"; "Educação: fora de uma zona de relativo conforto"; "Brasil: nação irmã"; 
"Espelhos: heróis, ídolos, gente admirável”; "A casa: em família"; "Crônica”).

Não é à toa que a crônica a iniciar o livro seja "Blimundo ou o mito fundador da cabo-verdianidade", pois ela destaca, além do mito que funda a identidade crioula já aludida no próprio título, a cultura oral, forte influência da África que faz com que as histórias internalizadas aflorem e direcionem os sentidos para as interpretações dos símbolos:

Desde criancinha que oiço as mais variadas versões da história do Blimundo, mas considero a versão que escolhi a mais bonita (...) Essa minha versão tem a seguinte leitura: em linguagem metafórica, o Blimundo é o africano trazido escravizado do continente para as ilhas, onde era a principal força de trabalho; o rei simbolizava o colonizador ouvindo a história do Blimundo e fazendo a sua interpretação, os filhos dos filhos dos nossos filhos poderão sempre saber donde vem esse povo mestiço que habita as ilhas.

Contudo esse mito vai mais longe. Explica por que no arquipélago se formou uma sociedade única mestiça, com interpenetração entre brancos e pretos que, vindos ambos de fora, aqui se encontraram; (...) que tanto nos distingue de outras sociedades, onde brancos e negros formaram cada um o seu gueto e mutuamente se excluíram, como por exemplo, na África do Sul, do apartheid de triste memória. (DUARTE, 2013, p. 30)

Ao relacionar as características da formação inicial da sociedade cabo-verdiana, a autora não nega a violência de sua origem, "do homem branco com a mulher negra ou com a mulher branca" (DUARTE, 2013 , p. 30 ), quando na palavra-escritura do mito 
fundador circulam tessituras da oralidade cabo-verdiana, no resgate e na manutenção da autêntica tradição. Com Joseph Campbell, reforço que o

campo simbólico se baseia nas experiências das pessoas de uma dada comunidade, num dado tempo e espaço. Os mitos estão tão intimamente ligados à cultura, a tempo e espaço, que, a menos que os mitos e as metáforas se mantenham vivos, por uma constante recriação através das artes, a vida simplesmente os abandona. (FLOWERS, 1990, p. 62)

As quatro crônicas seguintes, que fazem parte do capítulo "As ilhas, um país: ser cabo-verdiana" - "Santo Antão, terra mater", "São Nicolau, ilha pater", "São Vicente, cidade talássica" e "Santiago, casa transitiva" - misturam a memória aos espaços partidos das ilhas. Na primeira, a autora refaz o caminho marítimo desbravador, não dos colonizadores em suas expansões marítimas, mas o trilhado pela menina Vera, em férias, a enfrentar a viagem de São Vicente para Santo Antão, por horas e em frágeis e pequenas embarcações "que pareciam autênticas cascas de nozes a boiar num mar azul escuro denso e volumoso" (DUARTE, 2013, p. 32).

Embora a viagem de regresso fosse ainda mais terrível, pois junto aos passageiros, seguia toda a sorte de animais, que iam enriquecer os mercados de Mindelo ainda nos tempos coloniais, ao lado de crianças que choravam e passavam mal, os bons momentos 
desfrutados na ilha valiam a "via sacra", como a autora definiu a viagem. Na casa de Tia Mariazinha ouvia estórias, andava pelo canavial, chupava cana, comia mangas debaixo das mangueiras, nadava nas ribeiras para, ao cair da noite, "ouvir as assombrosas histórias de gongons, capotonas, canelinha e das bruxas, que anualmente se reuniam no Curral da Russa lá nos confins de Lagoa" (DUARTE, 2013, p. 34). Com Vera Duarte, também viajamos através de suas saborosas palavras na direção, agora, da Ilha de São Nicolau, conhecida como o berço da intelectualidade cabo-verdiana. A cronista a apresenta, lembrando que no passado era "uma ilha verde e nos seus pontos também ancoraram navios piratas em busca de suas riquezas" (DUARTE, 2013, p. 34), até vir a seca, uma constante em Cabo Verde.

São Vicente e seu porto representam a metonímica vocação das ilhas para partidas e chegadas, onde "sempre floresceram as tocatinas e as serenatas e que foi berço de vários movimentos literários, com especial destaque para o movimento claridoso" (DUARTE, 2013, p. 38) e onde nasceram talentos como os de B. Leza e Cesária Évora. Descrita pela autora como "ilha aberta ao mundo", na qual construiu a sua "casa transitiva”.

O capítulo intitulado "Mulheres" abriga grande número de crônicas que relatam o difícil dia a dia das cabo-verdianas em uma sociedade de base patriarcal. Assim acontece com "8 de março em Pingo Tchuva", 
na qual o hibridismo é encontrado no próprio título ao misturar a língua crioula com a portuguesa - processo antropofágico metonímico das culturas que se interpenetraram.

Em pouco tempo, as mulheres já se tinham disposto em círculo. Panos envoltos em plástico no regaço e sons de batuque começaram a encher os ares.

Sabú Vaz da Veiga, 60 anos, dez filhos, dominou o terreiro.

(...)Um ligeiro cheiro de aguardente começou a circular entre os convivas. Sabú Vaz da Veiga e outra dançadeira desafiaram-se, desenvolvendo a mais formidável dança de batuque que já me foi dado ver, num jogo inigualável de movimentos sincopados e gestos carregados de sensualidade.

Afastei-me um pouco para tomar as notas que já me ferviam no espírito. As crianças encantaram-se de me ver escrever e rodearam-me. Um velho marinheiro veio dizer-me que, em 1927, tinha estado em São Vicente, habitado a Rua dos Descobrimentos, e gostava das mulheres mindelenses. Disse também que sabia escrever, mas não tão bonito como eu. (DUARTE, 2013, p. 56)

Retomo a menção que a autora fez ao movimento claridoso, em transcrição anterior nesse momento de batuque, pois ao longo dos nove exemplares da Revista Claridade (1936-1966), como já venho afirmando em várias publicações, há a presença dessa forte herança africana, o que identifica a Claridade como acontecimento, para além do literário, político-cultural (como, aliás, igualmente o foi o Modernismo Brasileiro). Isso ocorre desde o primeiro número, 
que trouxe na capa a lantuna e o finaçom, dois batuques da Ilha de São Tiago, e principalmente, a partir do exemplar 6 (presente em todos os posteriores), as pesquisas de Félix Monteiro, investigador da cultura cabo-verdiana e dos festejos da tabanca, entre outras manifestações (LIMA, 2019).

A mulher como personagem central dessa dança reforça o seu lugar de guardiã da cultura crioula. É interessante notar que o leitor presencia o momento do nascimento da crônica que lê, quando Duarte cita o fato de ter se afastado um pouco para escrever. A curiosidade que desperta nas crianças indica a baixa escolarização nas ilhas, quando escrever ainda é algo muito destacado na sociedade de base oral. Ser uma mulher que redige gera a admiração do marinheiro galanteador, que afirma saber escrever, mas não como ela.

Em “Outras lutas: público e privado”, a crônica "Rir é o melhor remédio" restitui a essência do fazer cronístico sintonizado com o humor, com a leveza que, disfarçada de despretensão, toca em assuntos fundamentais. Dedicada às pessoas doentes, o seu objetivo é dizer que "a alegria cura", além dos médicos e dos tratamentos importantes, pois livra de doenças aqueles que têm a capacidade de alegrar-se com as alegrias dos outros. "Os cabo-verdianos, sobretudo os do barlavento, têm o bom hábito de cultivar o humor e riem-se de si mesmos (...) contrariamente a muitos 
que têm de ser ou parecer sérios para se valorizarem". (DUARTE, 2013, p. 79)

No "O estatuto do intelectual”, em "Educação: fora de uma zona de relativo conforto", é valorizada a formação educacional tardia no arquipélago, mas avançada em relação às outras colônias, que possibilitou o aparecimento de uma classe de escritores, ainda no século XIX. Definindo, inicialmente, o intelectual de forma universal como "aquele que vem fazendo um esforço ingente e dedicado, ao longo dos dias e à sombra das horas que poderiam ser dedicadas a coisas mais fáceis e talvez mais prazerosas" (DUARTE, 2013, p. 105), envereda, em seguida, na trilha dos encontros com os escritores das ilhas, incluindo os três fundadores da geração claridosa, gente de "nôs terra".

Aqui ela se volta para a sua própria trajetória, na qual atrela o ato de escrever à modéstia inerente ao cronista, repetindo no seu comportamento a simplicidade de seus modelos, pois conta que ao ser apresentada a Manuel Lopes, ainda menina, e perguntar-lhe se era escritor, ele lhe respondeu "é o que dizem, eu considero-me um simples contador de histórias".

Que um dia eu própria tenha sido levada a escrever é uma pulsão natural, um desejo, quem sabe inconsciente, de fazer a catarse e comungar-me com os outros, através da escrita. Que essa escrita um dia ou outro venha a lume é uma decorrência possível. Que daí alguém se tenha lembrado de me chamar intelectual é algo de que não me cabe a responsabilidade. (DUARTE, 2013, p. 104) 
Ao dedicar um capítulo para o Brasil, ela retoma a ligação de encantamento entre as duas nações, presente em depoimentos, homenagens, diálogos literários e em tantas outras manifestações ao longo do tempo, presentes de forma especial a partir do movimento claridoso. Em "As literaturas dos PALOP's no currículo escolar brasileiro", observa tanto que o início da sua paixão pela cultura brasileira se deu pelas literaturas de Jorge Amado, Machado de Assis, Manuel Bandeira e Guimarães Rosa, quanto narra a recepção da Literatura cabo-verdiana nas instituições brasileiras que visitou e pelos pesquisadores que conheceu, por ocasião de uma viagem que fez ao país. Acredita a autora que uma das causas para tal recepção tenha sido a lei 10.639/2003, que instituiu o ensino da cultura afro-brasileira nas escolas públicas e privadas. "Afinal, é o Atlântico cumprindo a sua vocação histórica de estrada cultural de levar e trazer". (DUARTE, 2013, p. 148)

"Espelhos: heróis, ídolos, gente admirável" contém um poema da autora dedicado a Amílcar Cabral ("O poema primordial"), personagem importante para a luta da independência de Cabo Verde, que está presente em várias outras crônicas do livro. Em "Amílcar, Amílcar!", a palavra assume a dimensão de homenagem dupla por conjugar dois tempos: o do mês do nascimento do herói e o da data em foi proclamada a independência de Guiné Bissau.

Unida a Cabo Verde, a Guiné fez parte da luta pela libertação do jugo colonial no partido fundado por 
Amílcar o PAIGC (Partido Africano para a Independência de Guiné e Cabo Verde), em 1956. 0 líder, assassinado em 1973, também foi poeta, aspecto que a escritora valoriza ao identificá-lo, para além da faceta de herói nacional, como "exímio homem de letras" que teceu "poemas carregados de esperança no amanhã em construção" (DUARTE, 2013, p. 159). Cita "Regresso", poesia musicada gravada pela cantora brasileira Alcione "em que ele fez a apologia da chuva". (DUARTE, 2013, p. 160). Outra crônica, que fecha o capítulo, "Mulheres pioneiras", menciona o apoio que o PAIGC, na presença de seu fundador, fornecia à emancipação do sexo feminino:

São dele as seguintes palavras: "há camaradas homens, alguns, que não querem entender que a liberdade para o nosso povo quer dizer liberdade também para as mulheres, a soberania para o nosso povo quer dizer que as mulheres também devem participar nisso, e que a força do nosso Partido vale mais na medida em que as nossas mulheres peguem teso para mandarem também, com os homens. (DUARTE, 2013, p. 167-168)

"A Casa, em família" assume a escritura-conversa que recupera a hermenêutica do cotidiano inserida na ambiência do privado. A palavra agora traduz os dias das experiências particulares que, se redimensionadas, assumem assunção mais ampla: a de abarcar outras histórias, contornos e tempos. Assim ocorre com "Ana", crônica com que a autora homenageia a irmã falecida, descrevendo a paisagem chuvosa da Guiné Bissau que 
mudara repentinamente de "verde denso" para um tom escuro, com folhas das árvores a rodopiar e chuva copiosa de grossas "gotas de água [que] despencavam dos céus e caíam com barulho no chão, nas árvores, no telhado das casas, fazendo uma sinfonia digna da mais harmoniosa das orquestras" (DUARTE, 2013, p. 176).

A relação da escritora com a chuva que de repente irrompe na Guiné, embora oriunda de experiência pessoal, assume percepção mais ampla, pois se refere ao hábito do cabo-verdiano de vivenciar a sofrida escassez pluvial do arquipélago, cuja seca matou milhares de fome, entre as décadas de 1930-1940.

Face à minha estupefação, a minha irmã explicou-me divertida, que era assim a chuva na Guiné. Grossa, quente, viva. Disse-me que essa era uma das razões que lhe faziam gostar tanto daquela terra que conhecera e amara de imediato. (DUARTE, 2013, p. 176)

Cabe ressaltar que essa era a primeira viagem da autora à Bissau. Ao se reencontrarem, Vera e Ana refazem os laços de quando nasceu a nação cabo-verdiana. "Demasiado cedo essa irmã nos deixou para fazer companhia ao nosso saudoso pai. Mas a lembrança dela vive festivamente em mim, acompanhada da copiosa chuva africana (...)" (DUARTE, 2013, p. 176). A morte de Ana parece, no plano do simbólico, romper o sonho de Amílcar de reunir Cabo Verde a Guiné Bissau, e na percepção da quadra feminina em que se insere a chuva - Ana, Vera, a Guiné e a África - a fecundação é 
evidente, das emoções, da memória, dos aromas, dos barulhos e da saudade.

0 capítulo final contém apenas uma crônica intitulada "Crônica: sobre a crônica" que não fugiu à regra da tradição de os cronistas se debruçarem sobre o seu próprio ofício. “Sei lá!”, datada com o ano de 1984, reflete sobre os dias e os seus personagens que lhe pedem, silenciosamente, para virarem palavras.

Sei lá! Sei lá se é fácil escrever... Até me parece que não. A vida é tão rica, a história tão cheia de acontecimentos, aqui ao meu lado o guerrilheiro em descanso, a vendedeira de torresmos ou a criança de ranho no nariz estão-me a pedir - gritantemente - que lhes escreva a história, que troque por letra de imprensa essa extraordinária sucessão de guerra e paz, fome e fartura, choro e alegria sobretudo, os caminhos percorridos. (...)

Sei lá se é fácil escrever...

0 que sei é que, sempre que puder e souber, irei trocar por letras de imprensa essa extraordinária sucessão de guerra e paz, fome e fartura, choro e alegria, que é a vida da gente. (DUARTE, 2013, p. 191)

É interessante notar, nesses momentos finais, que a escrita de Vera Duarte, por trazer muito de testemunho, assumiu naturalmente feição de crônica, pois a reflexão acima foi feita na década de 80 , antes de ela ter publicado o seu primeiro livro de poesia, em 1993, revelando a aproximação que sempre realizou, de uma forma ou de outra, entre a palavra e os dias. 


\section{Referências:}

ANDRADE, Oswald. Pau-brasil. 6 ${ }^{\text {a }}$ ed. São Paulo: Globo, 1998.

BENDER, Flora; LAURITO, Ilka. Crônica: história, teoria e prática. São Paulo: Scipione, 1993.

BRANCO, Lúcia Castello; BRANDÃO, Ruth Salviano. A mulher escrita. Belo Horizonte: Casa Maria, 1989.

CHEVALIER, Jean; GHEERBRANT, Alain. Dicionário de símbolos: mitos, sonhos, costumes, gestos, formas, figuras, cores, números. 13a ed., Rio de Janeiro: José Olympio, 1999. Tradução de Carlos Sussekind.

CANDIDO, Antonio. À guisa de Introdução: a vida ao rés do chão. In: SETOR DE FILOLOGIA DA FCRB (Org.). A crônica: o gênero, sua fixação e suas transformações no Brasil. Rio de Janeiro: Fundação Casa de Rui Barbosa, 1992, p. 13-22. DUARTE, Vera. A palavra e os dias. Belo Horizonte: Nandyala, 2013.

DUARTE, Vera. 0 canto da sereia ou a emergência da voz das mulheres na literatura cabo-verdiana. In: GOMES, Simone Caputo (Org.). Contravento, pedra-a-pedra: conferências do I Seminário Internacional de estudos cabo-verdianos. Praia: Biblioteca Nacional, 2015. p. 229-244.

DUARTE, Vera. As transformações no mundo e os seus reflexos na vida literária. In: SPINOLA, Daniel (Org.). I Encontro de escritores caboverdianos. Praia: Cabo Verde, 1994, p. 9-17.

FLOWERS, Betty Sue (Org.). 0 poder do mito. São Paulo: Palas Athena, 1999. Tradução: Carlos Felipe Moisés.

GOMES, Simone Caputo. A escrita literária de Dina Salústio e Vera Duarte: resistindo à persistência de um cânone de perspectiva masculina. Interdisciplinar: revista de estudo em língua e literatura, Universidade Federal de Sergipe, v 32, p. 227-242, jul-dez 2019. 
GOMES, Simone Caputo. Literopintar Cabo Verde: a criação de autoria feminina. Revista Crioula, Universidade de São Paulo, v. 3, p. 1-23, 2008.

GOMES, Simone Caputo. Cabo Verde: literatura em chão de cultura. São Paulo: Ateliê Editorial, 2008.

LIMA, Norma Sueli Rosa. (Re)visitando Claridade: o encantamento da poesia cabo-verdiana com o modernismo brasileiro. 2000. 212 f. Tese (Doutorado) - Curso de Letras, Universidade Federal Fluminense, Niterói, 2000.

LIMA, Norma Sueli Rosa. Literatura cabo-verdiana em trânsito. Soletras: revista de Pós-graduação em Letras e Linguística. UERJ, n. 38, v. 2, p. 339-362, 2019.

MBEMBE, Achille. Crítica da razão negra. $2^{\underline{a}}$ ed. São Paulo: N1 Edições, 2018. Tradução de José Juliano Gadelha.

MORRISON, Toni. A origem dos outros: seis ensaios sobre racismo e literatura. São Paulo: Companhia das Letras, 2019. Tradução de Fernanda Abreu.

ORLANDI, Eni Pulcinelli. Terra à vista. Discurso do confronto: velho e novo mundo. Campinas: Cortez, 1990. LARANJEIRA, José Luís Pires. Pós-colonialismo e Pós-modernismo em contexto pré-moderno e moderno - o local e o nacional nas literaturas dos cinco e as ilusões da literatura-mundo. Estudos Literários. Coimbra, v. 5, p. 17-47, Tradução de Fernanda Abreu.

ROZÁRIO, Denira. Vera Duarte. In: ROZÁRIO, Denira. Palavra de poeta: Cabo Verde e Angola, entrevistas, antologias, biobibliografias dos maiores poetas de Cabo Verde e Angola. Rio de Janeiro: Bertrand Brasil/Fundação Biblioteca Nacional, 1999. p. 91-102.

SÁ, Jorge de. A crônica. São Paulo: Ática, 1985.

SPIVAK, Gayatri Chakravorty. Pode o subalterno falar? Belo Horizonte: Ed UFMG, 2010. Tradução de Sandra Regina Goulart. 